\title{
Editor in the field The Coriell Institute for Medical Research
}

t doesn't take long for a visitor to the Coriell Institute for Medical Research (CIMR) to get to the heart of the place. Just steps from the lobby, a window onto the world's most important repository of cell lines reveals row after row of liquid nitrogen tanks holding more than one million frozen ampules of cells and DNA (pictured). On the other side of the glass, one wall of the facility features a map of the world with blue pushpins representing places to which Coriell's samples have been shipped, at a rate of more than 1,000 per week. The pattern of blue is a fair representation of biomedical research activity around the world, and is reflected in acknowledgments to Coriell in countless publications since the founding of the National Institutes of Health (NIH)-funded repository in 1964.

The Coriell Institute itself was chartered in 1953 as the South Jersey Medical Research Foundation Laboratory, and the bricks and mortar were officially dedicated in 1956 in Camden, New Jersey, in the wake of the development of the polio vaccine. The laboratory would eventually bear the name of its director, Lewis Coriell, previously of the Camden Municipal Hospital and the developer of tissue culture techniques that ultimately allowed poliovirus to be grown in culture. Coriell's expertise in tissue culture led to additional NIH funding in the early 1970s to establish the Human Genetic Mutant Cell Repository at the CIMR. The institute is now part of the Camden campus of the University of Medicine and Dentistry of New Jersey, which provides potential collaborators in addition to those in Philadelphia's biomedical research community, just a few minutes away on the opposite bank of the Delaware River.

Today, blood samples come in at a steady rate. Upstairs from the storage facility, accompanied by Jeanne Beck, director of the Coriell Cell Repositories, one can visit with the tissue-culture teams that carry the cells through bar coding, transformation, growth and freezing, with fail-safe procedures designed to ensure that backup samples are available. Cells are submitted from individuals with a wide array of genetic diseases (for a total of more than 8,000 such cell lines), complete with clinical information on the donors as well as ethnically matched control panels. The importance of the repositories to genetics and medicine is conveniently highlighted starting on page 31 of this issue, where we present a study in which CIMR's cells from individuals with Rett syndrome were used to assess the imprinting status of DLX5. Other samples are now of historic significance: the CIMR banked Nancy Wexler's collection of blood samples and cells from the storied Venezuelan family afflicted with Huntington disease.

As explained by the institute's president David Beck, an annual budget of some \$14 million funds an increasingly wide range of activities. These include participation in the HapMap project by banking DNA and cell lines from those individuals who are being genotyped. The CIMR also hosts New Jersey's umbilical cord blood bank, which has already been used to successfully treat seven individuals with life-threatening blood disorders, according to the institute's Amy Leach. Work on nonhuman primates is facilitated through the Integrated Primate Biomaterials and Information Resource, a partnership with the Zoological Society of San Diego and Princeton University established to create a repository of cells and DNA from every primate genus (including Clint, the chimpanzee whose genome has been sequenced). Finally, the CIMR has just announced a collaborative program with Israel's Technion to carry out comparative studies of stem cells from adult and embryonic sources. Institute stem cell researchers, including Rick Cohen, David Moscatello and Biagio Saitta, will lead this effort, which grows naturally out of existing CIMR research on neuronal stem cells, adipose stromal cells and cord blood stem cells.

In return for the samples that come in from around the world, the CIMR exports not only essential materials but also its expertise and best practice in bar coding, tissue culture and information management. As such, what began as a relatively small institute, in an unlikely place, will continue to have a long reach.

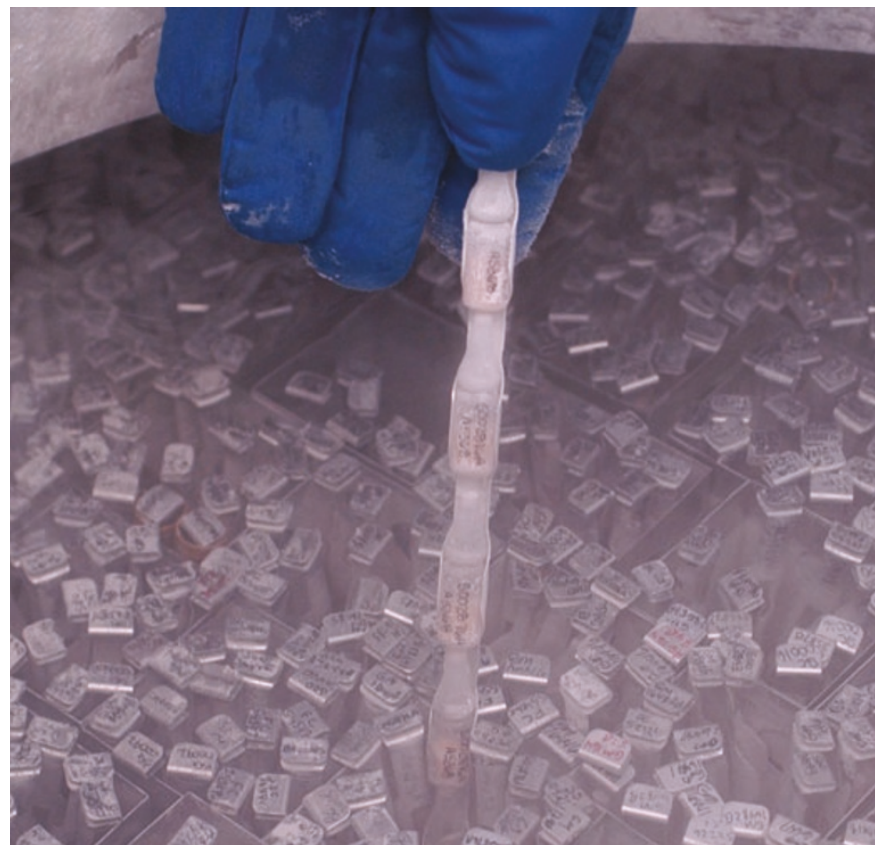

